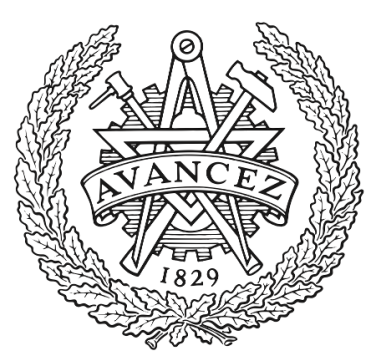

\title{
CHALMERS
}

UNIVERSITY OF TECHNOLOGY

\section{Injection Molding and Appearance of Cellulose-Reinforced Composites}

Downloaded from: https://research.chalmers.se, 2023-04-26 10:53 UTC

Citation for the original published paper (version of record):

Forsgren, L., Berglund, J., Thunberg, J. et al (2020). Injection Molding and Appearance of Cellulose-Reinforced Composites. Polymer Engineering and Science, 60(1): 5-12.

http://dx.doi.org/10.1002/pen.25253

N.B. When citing this work, cite the original published paper. 


\title{
Injection Molding and Appearance of Cellulose-Reinforced Composites
}

\author{
Lilian Forsgren $\mathbb{D}^{\mathrm{D},}{ }^{1}$ Johan Berglund, ${ }^{1,2}$ Johannes Thunberg, ${ }^{1}$ Mikael Rigdahl, ${ }^{1}$ Antal Boldizar ${ }^{1}$ \\ ${ }^{1}$ Department of Industrial and Materials Science, Chalmers University of Technology, Gothenburg, Sweden \\ ${ }^{2}$ Department of Manufacturing, RISE IVF, Mölndal, Sweden
}

\begin{abstract}
Composite materials based on an ethylene-acrylic acid (EAA) copolymer and $20 \mathrm{wt} \%$ cellulose fibers were compounded by two runs in a twin-screw extruder. The composite material with cellulose fibers $(C F)$ and a reference of unfilled EAA were injection molded into plaques using three different temperature profiles with end zone temperatures of $170^{\circ} \mathrm{C}, 200^{\circ} \mathrm{C}$, and $230^{\circ} \mathrm{C}$. The injection molded samples were then characterized in terms of their mechanical properties, thermal properties, appearance (color and gloss), and surface topography. The higher processing temperatures resulted in a clear discoloration of the composites, but there was no deterioration in the mechanical performance. The addition of cellulose typically gave a tensile modulus three times higher than that of the unfilled EAA, but the strength and strain at rupture were reduced when fibers were added. The processing temperature had no significant influence on the mechanical properties of the composites. Gloss measurements revealed negligible differences between the samples molded at the different melt temperatures but the surface smoothness was somewhat higher when the melt temperature was increased. In general, addition of the cellulose to the EAA reduced the gloss level and the surface smoothness. POLYM. ENG. SCI., 60:5-12, 2020. () 2019 Society of Plastics Engineers
\end{abstract}

\section{INTRODUCTION}

Cellulose fibers have a potential and promising possibility to replace fossil-based materials in polymer composites in a number of applications. The automotive, construction, and packaging industries have all increased the use of natural fiber composites during the last two decades [1-4]. Cellulose has a relatively low density and exhibits potentially good mechanical properties. Further positive aspects are its abundance, renewability, biodegradability and relatively low cost. Using cellulose fibers (or natural fibers) as a reinforcing element would be a more sustainable alternative than the components conventionally used today, such as glass or carbon fiber, cf. Shalwan and Yousif [5] and the idea of using cellulose-reinforced polymer materials is certainly not new, cf. [6-12].

However, there are challenges encountered with the use of cellulose fibers in polymer composites; they are hydrophilic, prone to form agglomerates and difficult to disperse well in most rather hydrophobic polymer matrices. The incompatibility between the hydrophilic cellulose and the hydrophobic polymer affects the adhesion between the reinforcement and the matrix and hence also

Correspondence to: A. Boldizar; e-mail: antal.boldizar@chalmers.se Contract grant sponsor: Chalmers University of Technology. contract grant sponsor: Swedish Research Council Formas.

DOI 10.1002/pen.25253

Published online in Wiley Online Library (wileyonlinelibrary.com).

(C) 2019 Society of Plastics Engineers the properties of the composite material $[13,14]$. Most of the conventional methods used for processing thermoplastic components require elevated temperatures, but cellulose fibers are sensitive to thermal degradation, even at rather low temperatures. This degradation, which is markedly affected by the ambient conditions, involves a reduction in the molecular weight, the generation of free radicals and carbonyl, carboxyl and peroxide groups and also color changes, cf. Sapieha et al. [15]. The yellowing of cellulose has been associated with the formation of chromophores due to oxidation of the material [16]. The degradation of cellulose may take place at quite low temperatures; Shafizadeh and Bradbury [17], for example, studied the degradation kinetics of cotton cellulose at $150^{\circ} \mathrm{C}$ in different environments and in a series of model experiments, Mosca Conte et al. [16] aged cotton linters at $90^{\circ} \mathrm{C}$ for long times (up to $48 \mathrm{~h}$ ) under different conditions and concluded that the optical degradation could be associated with the formation of carbonyls on aldehydic groups and conjugated diketones. In a study of thermal discoloration, Matsuoka et al. [18] noted a clear correlation between the amount of reducing end groups in cellulose and the color change at elevated temperatures. There is an important interplay between the temperature and the exposure time with regard to the progress of the degradation. It should also be noted that pulp fibers (which are used in the present study) can contain various amounts of lignin and hemicellulose, depending on the processing of the pulp fibers, which may be subjected to thermal degradation and thus contribute to the discoloration at elevated temperatures.

During processing, thermal degradation of the cellulosic fiber may lead to an undesired discoloration of the polymer composite and may also affect its mechanical performance. The discoloration has a direct impact on the appearance of the product, which is the focus of this study, and it is considered essential to clarify to what extent the thermal degradation affects the visual appearance and surface characteristics of natural fiber composites processed by conventional processing methods such as injection molding. The perceived quality of an object is closely related to its appearance, and a better understanding of the relationships between surface appearance, thermal stability and processing conditions is certainly to be aimed for in this context. Quality is not nowadays solely related to good performance and durability, but also to appearance.

The appearance of an object is obviously dependent on size, shape, and material selection, but the processing method and parameters also influence the appearance and the surface texture of the object. The environment, for example, the light conditions and surrounding objects, also affect the perception of a component. It is thus somewhat complicated to discuss and measure appearance since it is highly dependent on the context. As a starting point, it can, however, be argued that there are three descriptors that relate to the surface appearance of an object: 
gloss, surface texture and color. In injection molding, the process parameters and the reproduction of the mold surface affect all these three descriptors and it is essential to know how [19]. Ariño [20] investigated aspects of appearance characteristics in terms of color, gloss, and texture in the case of polymers, and especially for the injection-molded textured surfaces used in car interiors. Using a cellulose-reinforced polymeric material, possible enhanced changes in color and surface texture can be related to the limited thermal stability of cellulose. Ignell et al. [21] also studied the effect of the injection molding process on the color, gloss and texture of polymeric components and they noted, for example, that a rougher surface appears lighter, even though the composition of the material has not changed. This is related to increased proportion of light diffusely reflected from the surface. The relationships between the appearance, color, gloss, and texture are rather complex and must be considered when designing or producing a product.

The cellulose-containing material used in this study has been thoroughly investigated previously by Ariño and Boldizar [22-25] with respect to compounding techniques, injection molding, and mechanical properties. The most common techniques used to manufacture this type of composite material are extrusion mixing followed by injection molding or compression molding, but compounding this type of material involves problems, predominantly regarding the continuous feeding of the fibers into the equipment, thermal degradation, fiber breakage, and the dispersion of fibers in the matrix [26]. Ariño and Boldizar showed that the melt processing of the cellulose fiber composite had a great influence on both the fiber dispersion and the final fiber length [24]. They also showed that introducing the cellulose fibers into the mixing extruder in the form of a tissue sheet gave promising results in terms of dispersion and continuous feeding [22]. The composite material used in the present study was produced by this compounding method [22], using a two-layered tissue for the fiber dispersion in an ethylene-acrylic acid (EAA) copolymer matrix. In the present study, the focus is on the thermal degradation of the composites during processing and its effects on the appearance and perceived quality. For this purpose, plaques of the cellulosereinforced EAA were injection molded using different melt temperatures, and the appearance of the plaques was assessed in terms of color, gloss, and surface roughness. The mechanical performance of the components was also evaluated.

\section{EXPERIMENTAL}

Materials

The matrix material used was an EAA copolymer, PRIMACOR 3540 from Dow Chemical Company, with an acrylic acid content of $7 \%$. This EAA grade had a number average molecular weight $\left(M_{n}\right)$ of $16,100 \mathrm{~g} / \mathrm{mol}$, a density of $0.932 \mathrm{~g} / \mathrm{cm}^{3}$, and a melt flow rate $(190 \mathrm{C} / 2.16 \mathrm{~kg}$, ISO1133) of $8 \mathrm{~g} / 10 \mathrm{~min}$.

The cellulose fibers $(C F)$ used in the composite came from a two-layered tissue with $100 \%$ primary fibers from Metsä Tissue, Sweden/Finland. The tissue sheet had a grammage of $34 \mathrm{~g} / \mathrm{m}^{2}$ and consisted of $25 \%$ softwood and $75 \%$ birch fibers and was free from any additives.

\section{Compounding}

The compounding of cellulose and EAA was performed as outlined by Ariño and Boldizar [22], using a corotating twin- screw extruder, Werner \& Pfleiderer ZSK 30M9/2 (Stuttgart, Germany) with a screw diameter of $30 \mathrm{~mm}$ and a screw length of $966 \mathrm{~mm}$. The extruder had five heating zones along the cylinder and one heating zone for the die, and the temperature profile from hopper to die was $100^{\circ} \mathrm{C}, 130^{\circ} \mathrm{C}, 140^{\circ} \mathrm{C}, 140^{\circ} \mathrm{C}, 150^{\circ} \mathrm{C}$, and $150^{\circ} \mathrm{C}$. The tissue was dried at $75^{\circ} \mathrm{C}$ for 3 days before being introduced into heating Zone 3 through a tube connecting the dryer with the extruder. The screw speed was $96 \mathrm{rpm}$ and the tissue feed rate was balanced in relation to the screw speed in order to obtain a cellulose content of $20 \mathrm{wt} \%$ in the final composite material. The material was passed through the twin-screw extruder a second time with the same settings in order to promote the fiber dispersion. The composite material was dried at $60^{\circ} \mathrm{C}$ for approximately 1 week before the injection molding, but without any measurable weight loss. No color change was noted due to the compounding, indicating insignificant thermal degradation. As a reference material, the unfilled EAA copolymer was used.

\section{Injection Molding}

An injection molding machine, Arburg ALLROUNDER 221M-250-55 (Austria), was used to produce quadratic test plates with dimensions of $64 \times 64 \times 1.5 \mathrm{~mm}^{3}$. The molding machine had five heating zones along its barrel. Three different temperature profiles were used for both the composite material and the unreinforced EAA, see Table 1, with increasing temperatures from the first heating zone along the screw to the final heating zone at the nozzle. The injection-molded materials (plaques and test bars) are denoted 170, 200, and 230 referring to the melt temperature of the last two zones. It is well known that the actual temperature of the melt exiting the nozzle can be significantly different from the setting, due, for example, to viscous heating.

The mold temperature was set to $25^{\circ} \mathrm{C}$ and the injection pressure to $750 \mathrm{bar}(75 \mathrm{MPa})$. The holding pressure was $800 \mathrm{bar}$ (80 MPa) and the backpressure was $15 \mathrm{bar}(1.5 \mathrm{MPa})$. The circumferential screw speed was set to $20 \mathrm{~m} / \mathrm{min}$. The sprue from the cylinder nozzle to the cavity diverged from a diameter of $4 \mathrm{~mm}$ to a diameter of $7 \mathrm{~mm}$ along the sprue length of $54 \mathrm{~mm}$, followed by an $18 \mathrm{~mm}$ long runner with a cross section of $40 \mathrm{~mm}^{2}$ and a rectangular cavity gate having a $8 \times 1,5 \mathrm{~mm}^{2}$ cross section and a land length of $1 \mathrm{~mm}$. The injection speed was set to $50 \mathrm{~cm}^{3} / \mathrm{s}$ while filling the sprue and reduced to $20 \mathrm{~cm}^{3} / \mathrm{s}$ when filling the mold cavity.

The injection molding cycle time was $64 \mathrm{~s}$, including $10 \mathrm{~s}$ holding time, $30 \mathrm{~s}$ cooling time, and a pause of $20 \mathrm{~s}$ with open mold before starting the next cycle. After every fifth cycle, the next injection volume was ejected outside the mold and the surface temperature of the melt at ejection was measured with a heat camera (FLIR i7) situated $10 \mathrm{~cm}$ above the die. With EAA, the surface temperature of the ejected melt was in general about $20^{\circ} \mathrm{C}$ lower than the set temperature of the last heating zone, whereas in the case of the $C F$ melts, the decrease was about $10^{\circ} \mathrm{C}$. The next seven moldings were then rejected before another five molded samples were taken. At the start of the injection molding series,

TABLE 1. Temperature zones for the three different processing profiles used.
170

200

230 $40^{\circ} \mathrm{C}-150^{\circ} \mathrm{C}-150^{\circ} \mathrm{C}-170^{\circ} \mathrm{C}-170^{\circ} \mathrm{C}$ $40^{\circ} \mathrm{C}-190^{\circ} \mathrm{C}-190^{\circ} \mathrm{C}-200^{\circ} \mathrm{C}-200^{\circ} \mathrm{C}$ $40^{\circ} \mathrm{C}-220^{\circ} \mathrm{C}-220^{\circ} \mathrm{C}-230^{\circ} \mathrm{C}-230^{\circ} \mathrm{C}$ 
the first 20 samples were discarded, before the process was considered stable.

\section{Mechanical Properties}

The tensile properties of test bars were measured at $25^{\circ} \mathrm{C}$ at a strain rate of $6 \mathrm{~mm} / \mathrm{min}$ using a Zwick/Z2.5 tensile tester equipped with a $500 \mathrm{~N}$ load cell. The tensile test bars with a gauge length of $40 \mathrm{~mm}$ were cut from the midsection of the injection-molded plaques, with the gauge length oriented in the injection direction. Three test bars were cut from each plaque and kept in a conditioned environment at $25^{\circ} \mathrm{C}$ and $55 \%$ relative humidity for at least 4 days prior to the tensile tests. Average values of the tensile modulus, the stress at break, and the strain at break are reported.

\section{Appearance}

The color of the plaques was measured in terms of the difference from the reference using a Datacolor 600 spectrophotometer with a $9 \mathrm{~mm}$ diameter opening and a $\mathrm{d} / 8^{\circ}$ spherical measurement device. The color was expressed in the 1976 CIELAB system [27] with coordinates $L^{*}$ (lightness), $a^{*}$ (red-green), and $b^{*}$ (yellow-blue). The lightness $L^{*}$ ranges from 0 (black) to 100 (white), $-a^{*}$ is green, $+a^{*}$ red, $-b^{*}$ is blue, and $+b^{*}$ yellow. All color measurements were performed with a white paper background to ensure equal conditions since the unfilled EAA samples (reference) were quite transparent. Each reported value is an average of three measurements at different positions on a plaque.

The gloss was measured with a BYK Gardner micro-TRI-gloss at an incidence angle of $60^{\circ}$ at room temperature. The gloss of the white paper sheet used as a background to ensure equal conditions was also measured. The measurements were performed with the incident light beam perpendicular to the main direction of the melt flow during the injection. Each reported value is an average of three measurements.

\section{Surface Roughness}

The surface topography was characterized using an S Neox optical instrument from Sensofar (Spain). The measurement mode of Confocal Fusion [28] was used, which is a combination of Imaging Confocal Microscopy [29] and Focus Variation [29], considered suitable for use on surfaces containing both smooth and rougher regions with steep angles [28, 30]. A $20 \times$ objective lens with numerical aperture 0.45 was used together with a annular light. Stitched areas of $1.53 \times 1.15 \mathrm{~mm}^{2}$ (x-y plane) were measured with a $0.645 \mu \mathrm{m}$ lateral resolution. The measured datasets were treated in the following way to create S-L surfaces for evaluation [31]:

1. Noise reduction (median denoising filter, $5 \times 5$ pixels window), $S$ filter, creating primary surfaces.

2. Form removal (polynomial of third degree), F operator, creating $\mathrm{S}-\mathrm{F}$ surfaces.

3. Thresholding to remove remaining spikes $(0.01 \%-99.99 \%)$.

4. Filling in of nonmeasured points (interpolation using a smooth shape).

5. High-pass filter to reduce replicated grinding marks from the mold (robust Gaussian filter, nesting index $0.08 \mathrm{~mm}$ ), L filter, finally creating the S-L surfaces.

The parameters selected for evaluation were [31, 32]:
1. $S_{q}$-root-mean-square height of the surface relative to a given plane. The standard deviation of the height distribution $S_{q}$ is strongly related to the arithmetic mean height $S_{a}$.

2. $S_{\text {tr }}$-texture aspect ratio of the surface, taken as a measure of uniformity of the surface texture. The $S_{\text {tr }}$ parameter has a value between 0 and 1 and is unitless. An isotropic surface has an $S_{\text {tr }}$ value close to 1 , whereas a strongly anisotropic surface has an $S_{\text {tr }}$ value near 0 .

3. $S_{\mathrm{dq}}$-root-mean-square gradient of the surface. $S_{\mathrm{dq}}$ was calculated as a root-mean square of slopes at all points, having a positive unitless value. A completely flat and level surface would have a value of 0 , and a rough surface would have an $S_{\mathrm{dq}}$ value greater than 0 .

All topography data processing and parameter calculations were made according to ISO 25178 [31] using MountainsMap ver. 7.4.8341 software from Digital Surf (France). Each surface was characterized at five different positions in the plane of the plaques. In the results, mean values together with $95 \%$ confidence intervals are presented. For one of the surfaces, a repeated set of measurements and analyses was performed with a duplicate sample to investigate possible differences between duplicate samples. This investigation showed that the surface topographies of the duplicate samples were very similar.

\section{Thermogravimetric Analysis}

Thermogravimetric analysis (TGA) was used to measure the onset of thermal degradation of both the composites with cellulose fibers, the unfilled EAA matrix and the tissue sheet. Approximately, $10 \mathrm{mg}$ samples were heated from $25^{\circ} \mathrm{C}$ to $500^{\circ} \mathrm{C}$ at a heating rate of $5^{\circ} \mathrm{C} / \mathrm{min}$ using a TGA/DSC $3+$ Star system (Mettler Toledo, Switzerland). Measurements were made both in air and in nitrogen, at a flow rate of $20 \mathrm{~mL} / \mathrm{min}^{1}$.

\section{RESULTS AND DISCUSSION}

\section{Injection Molding and Visual Appearance}

An increase in the injection molding temperature had a marked influence on the color of the cellulose-containing plates, as shown in Fig. 1. These specimens were yellowish already at a melt temperature of $170^{\circ} \mathrm{C}$ (last two temperature zones) and became darker when the melt temperature was increased. The appearance of the unfilled EAA, on the other hand, did not seem to be affected visually by the processing temperature. The EAA samples were more or less transparent, regardless of the melt temperature. Note that, the plaques were visually quite homogeneous, indicating a successful dispersion of the cellulose fibers using the adopted compounding procedure.

When the melt temperature was increased, the cellulosereinforced material showed a tendency to foam at the higher temperatures, possibly due to some humidity in the material, but further drying did not reduce this foaming tendency. The foaming tendency was only observed without pressurization, for example, in the melt before injection. With the high-pressure during injection and holding in the mold, no foaming or bubbles were observed. The EAA plaques tended to stick to the mold surfaces, which affected the surface of the molded plates. At higher melt temperatures, the cellulose-reinforced composites also adhered to the mold surface, affecting the surface texture to some extent. These areas were excluded when the color, gloss and texture of the surfaces were evaluated. A mold release agent was used to 


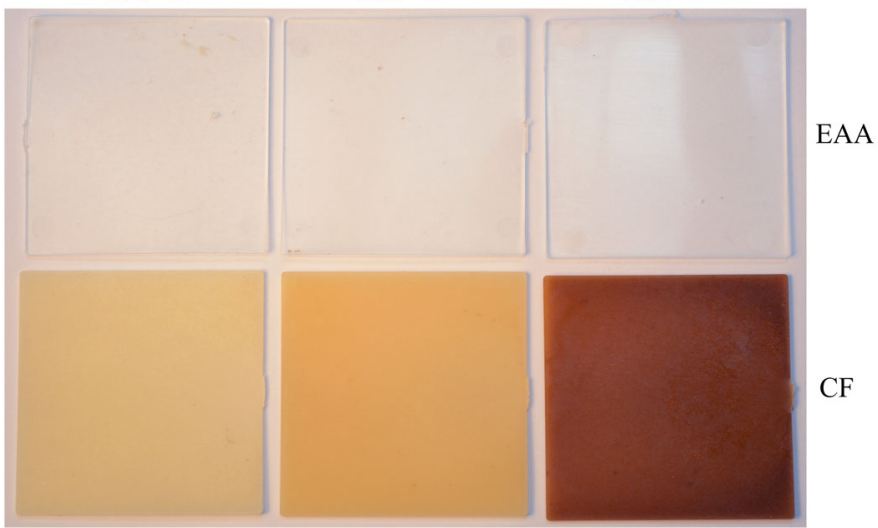

FIG. 1. Injection-molded cellulose-reinforced composites produced at three different processing temperatures compared to the unfilled matrix material treated at the same temperatures. [Color figure can be viewed at wileyonlinelibrary.com]

reduce the adhesion, but it was not sufficient enough to eliminate it completely.

\section{Mechanical Properties}

The tensile measurements showed that the elastic modulus increased when the EAA matrix was reinforced with cellulose, as shown in Fig. 2. However, the modulus was not affected by the processing temperatures, either for the unfilled EAA matrix, or for the composite.

There were some differences in the stress-strain behavior between the materials, which is shown in Fig. 3. In the unreinforced matrix, an increase in the melt temperature led to an increase in both stress at break and strain at break, see also Fig. 4. Reinforcement with cellulose fibers had no major effect on the stress at break; it was of the order $16-17 \mathrm{MPa}$, regardless of the processing temperature. This was comparable to the strength of the matrix material, although it was somewhat lower than that of the unfilled EAA, injection molded at $230^{\circ} \mathrm{C}$. The strengths of the

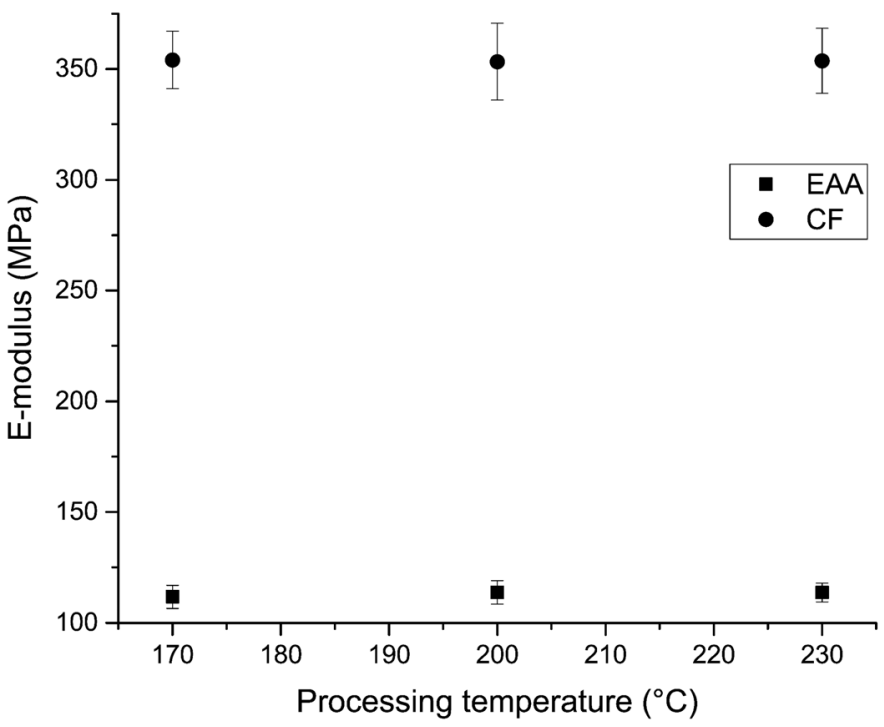

FIG. 2. The elastic modulus of the injection-molded composites and of the unfilled EAA manufactured at different processing temperatures.

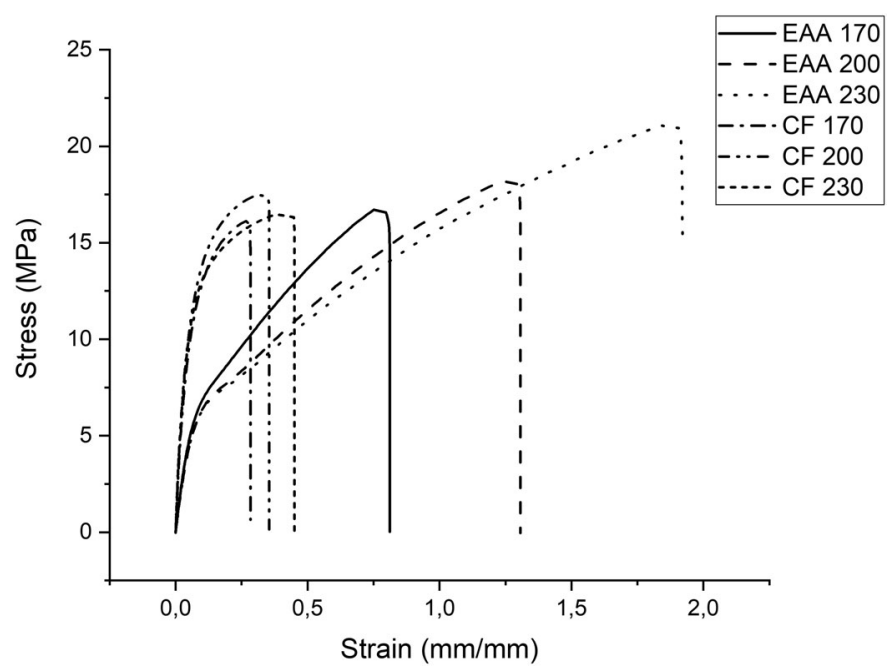

FIG. 3. Stress-strain curves for the composites and the unfilled EAA matrix, injection molded at different processing temperatures.

composites were also similar to the values reported by Ariño and Boldizar [22]. The strain at break was clearly lower for the cellulose-containing composites than for the unfilled polymer, that is, they were more brittle, cf. $[7,9,22,33]$. The processing temperature had no marked influence on the strain at failure, see Fig. 4.

The effect of the processing temperature on the mechanical properties of the cellulose-reinforced composites can be quite complex. For example, Sapieha et al. [15] reported an increase in yield stress for low density polyethylene filled with $30 \mathrm{wt} \%$ alpha-cellulose fibers when the processing temperature during compounding was raised from $150^{\circ} \mathrm{C}$ to $225^{\circ} \mathrm{C}$. At higher temperatures, there was a decrease in the yield stress. The processing times used were, however, quite long (up to $20 \mathrm{~min}$ ) compared to the cycle time of the present injection molding. Sapieha et al. [15] also noted a significant darkening of the specimens as the processing temperature increased. The improvement in mechanical performance was attributed to oxidation at the interface between the fibers and the matrix, enhancing the adhesion between the components. This is in contrast to the findings of Klason et al. [7], who studied the mechanical properties of thermoplastics reinforced with cellulosic fillers and the discoloration due to the processing. Their specimens were produced by compounding the polymer and the cellulosic material in a mixing extruder (residence time about $100 \mathrm{~s}$ ) followed by injection molding. They observed only small effects on the mechanical properties from the melt temperature, but the color changes were significant, in line with the results obtained in the present study, so it may be concluded that the thermal degradation of cellulose can lead to a discoloration of the composite material, but this is not necessarily accompanied by a deterioration in mechanical performance. For the latter to take place, the degradation must apparently proceed further.

The increase in tensile strength at break and in the strain at break of the unfilled EAA with increasing melt temperature was somewhat unexpected. Using differential scanning calorimetry, it was concluded that these changes could not be attributed to a change in the degree of crystallinity, which was 19\%-20\%, regardless of the processing temperature. Further studies based on 

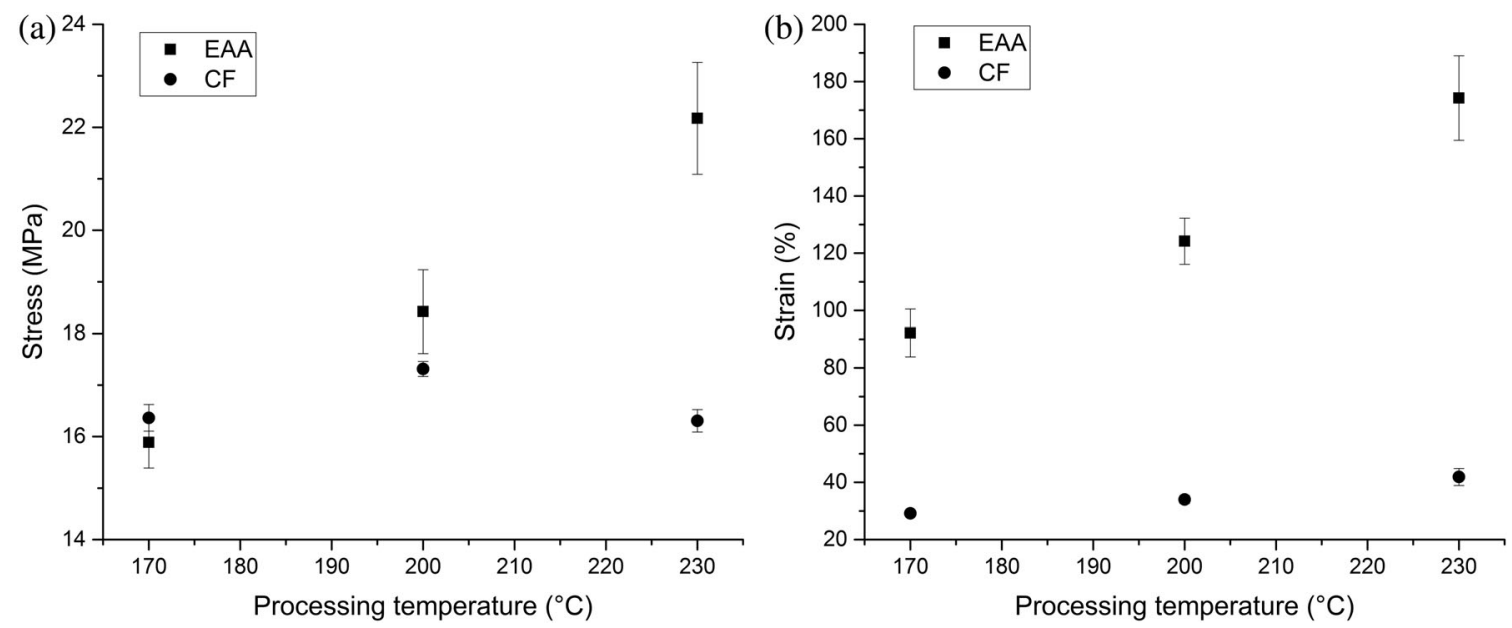

FIG. 4. The stress at break (left) and the strain at break (right) for the composites and the unfilled EAA, injectionmolded at different processing temperatures.

shrinkage measurements and polarized light microscopy revealed some difference in orientation between samples molded at different melt temperatures, and this can contribute to the observed behavior. It may be speculated as to whether interactions associated with the acrylic acid comonomer can set up a "network" structure in the samples. The processing temperature could then, after solidification, affect the structure and account for part of the change in mechanical properties. This suggest that the structure of the copolymer resembles in a sense that of its ionomers, cf. [34]. In the case of the composites, the insensitivity of the strength and strain at rupture to the melt temperature indicates that these properties are primarily determined by the cellulose content and by the properties of the interface between the matrix and the fibers.

\section{Appearance}

The results of the color measurements are summarized in Table 2. The unfilled polymer exhibited a high lightness $L^{*}$ and tended somewhat towards red and blue. The processing temperature had no major effect on the color of the EAA, as shown in the table, in contrast to the results obtained for the composite materials, where the melt temperature had a strong effect on the color. Already at the lowest processing temperature $\left(170^{\circ} \mathrm{C}\right)$, there was a clearly visible color difference between the unfilled EAA and the composite, and the transparency of the unfilled polymer was lost, cf. also Fig. 1. When the processing temperature was increased, the lightness of the composites decreased as they developed a more yellowish appearance as indicated by the $b^{*}$ coordinate.

TABLE 2. The color coordinates of the unfilled EAA and of the composite materials, injection-molded at different process temperatures.

\begin{tabular}{lccc}
\hline & CIE $L^{*}$ & $\mathrm{CIE} a^{*}$ & $\mathrm{CIE} b^{*}$ \\
\hline EAA 170 & 84.7 & 2.36 & -3.85 \\
EAA 200 & 85.3 & 2.44 & -3.42 \\
EAA 230 & 85.8 & 2.46 & -3.57 \\
$C F$ 170 & 72.8 & -1.39 & 6.17 \\
$C F$ 200 & 68.0 & -1.97 & 26.63 \\
CF 230 & 43.3 & 14.31 & 23.34 \\
\hline
\end{tabular}

With a melt temperature of $230^{\circ} \mathrm{C}$, the composite exhibited quite a strong increase in redness. The color changes with increasing processing temperature are presumably associated with thermal degradation of the cellulosic fibers. The standard deviations of the measurements were: $L^{*}$ - less or equal to $0.5 ; a^{*}$-less than $0.15 ; b^{*}$-less than 0.2 (with the exception of CF230 which exhibited a value of 0.64 ).

The gloss of the samples was also measured with a white paper background. The differences in gloss were rather small, the greatest difference being between the unfilled EAA samples and the cellulose-reinforced samples. The processing temperature appeared to have only a minor effect on the gloss level, as shown in Table 3, and the lowest gloss value being noted for the composite material injection-molded at the highest temperature $\left(230^{\circ} \mathrm{C}\right)$. The standard deviations of the measured gloss values were less than or equal to 1 gloss unit. It should be noted that the gloss values, especially in the case of the unfilled EAA, can only be used for an internal comparison, since the white paper background may influence the measured gloss. The same applies to the color measurements on the unfilled EAA.

\section{Surface Roughness}

Examples of the surface topographies are shown in Figs. 5 and 6 for EAA 170 and $C F$ 170, respectively. The calculated surface roughness parameter values are summarized in Table 4. In general, the EAA surfaces showed no significant differences in surface parameters with different processing temperatures. The

TABLE 3. The gloss of the unfilled EAA and the composite materials, injection-molded at different processing temperatures.

\begin{tabular}{lc} 
Sample & Gloss $(\%)$ \\
\hline White paper background & 3.9 \\
EAA 170 & 12.8 \\
EAA 200 & 15.3 \\
EAA 230 & 15.9 \\
$C F$ 170 & 7.9 \\
$C F$ 200 & 7.6 \\
$C F$ 230 & 6.3 \\
\hline
\end{tabular}




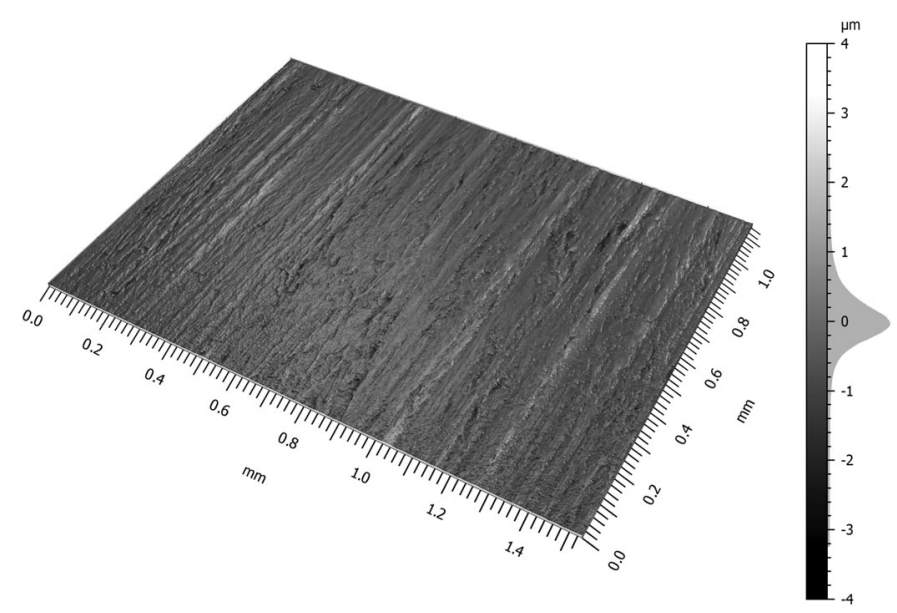

FIG. 5. Example of surface roughness measurement on EAA 170.

composite surfaces, as a group, were, however, significantly different from the EAA surfaces. Differences between the $C F$ surfaces were also observed. For example, evaluation of $S_{q}$, the root-mean-square height of the surface, showed that the $C F$ surfaces were rougher than the EAA surfaces, which is also reflected in the gloss values. The surfaces of the composites became less rough with increasing processing temperature, probably due to a better replication of the relatively smooth mold surface, cf. [35] although this had no effect on the measured gloss, Table 3, probably because the gloss of the composite surfaces was very low. In the case of textured polymeric surfaces, Ignell et al. [21] reported that a darker object exhibited a somewhat lower gloss than a lighter object. This effect may contribute to the slightly lower gloss of CF230, but the difference between the gloss values is very small.

The texture aspect ratio of the surface, $S_{\text {tr }}$, indicated that the EAA-surfaces were highly anisotropic with values close to 0 . A visual assessment of the surfaces, shared that traces of the mold, such as marks from grinding and polishing, were clearly present and unidirectional, see Fig. 5, for EAA 170. In Fig. 6 for $C F$ 170 , this unidirectional texture can still be observed, but it is broken up by a random structure of cavities, possibly caused by cellulose fibers close to the surface of the specimen. This causes the $S_{\text {tr }}$ values to increase and indicating an overall more isotropic texture.

The values of $S_{\mathrm{dq}}$, the root-mean-square gradient of the surface, revealed the same trend as for $S_{q}$, that is, low values, insensitive to the processing temperatures in the case of the unfilled EAA specimens and higher values for the composites, which decreased somewhat with increasing process temperatures. $S_{\mathrm{dq}}$ is

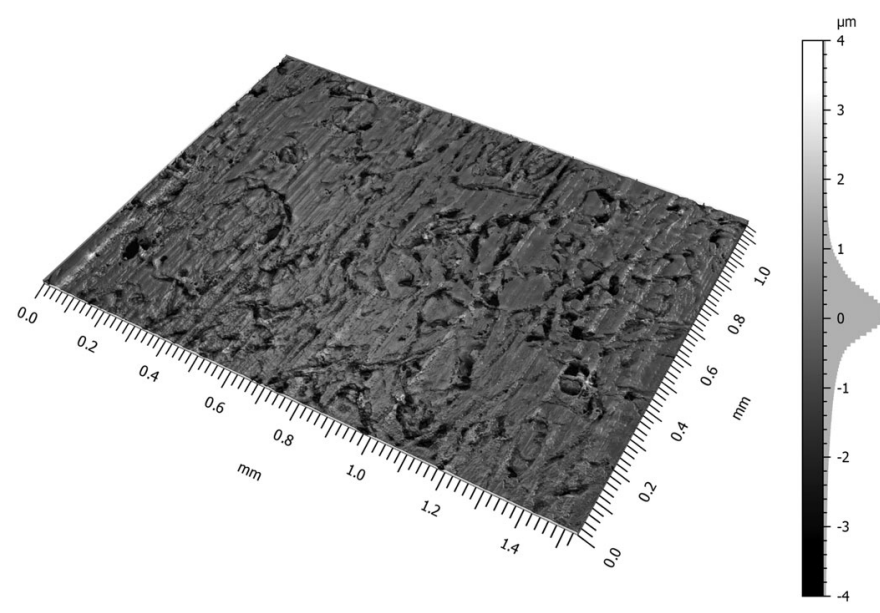

FIG. 6. Example of surface roughness measurement on $C F 170$.

a measure of the complexity of the surface, especially on smaller scales, or shorter wavelengths, and has been related to the optical appearance. A surface with a high $S_{\mathrm{dq}}$ is likely to exhibit more diffuse light reflection than a surface with a low $S_{\mathrm{dq}}$. In principle, a decrease in the proportion of diffusely reflected light would be perceived as a decrease in lightness, cf. [21,36], but in the present case, the substantial decrease in $L$ for CF230 is probably mainly due to thermal degradation.

\section{Thermal Properties}

The TGA measurements showed no significant discrepancies in thermal stability between materials of different processing history, that is, the degradation behavior was more or less the same for specimens of the same type made with different injectionmolding temperatures. Figure 7 shows the TGA curves for EAA 230, $C F$ 230, and the tissue sheet when the measurements were carried out in air. The thermal stability decreased when the cellulose fibers were incorporated into the EAA matrix in proportion to the amount of cellulose which had a lower resistance to temperature. On the other hand, the EAA matrix clearly gave better thermal stability to the cellulose fibers when they were dispersed in the matrix since the composite could withstand temperatures up to approximately $235-245{ }^{\circ} \mathrm{C}$ before the onset of degradation. The initial small weight decrease in the case of the cellulose fibers, noted in Fig. 7, was probably associated with a loss of water when approaching $100^{\circ} \mathrm{C}$. The degradation behavior changed slightly when the air was replaced by nitrogen and, as expected, the thermal stability was somewhat better in nitrogen than in air.

TABLE 4. Calculated surface roughness values. Mean values of five measurements on each surface with $95 \%$ confidence intervals.

\begin{tabular}{|c|c|c|c|c|c|c|}
\hline & $S_{q}(\mu \mathrm{m})$ & $S_{q}$ conf. int. $(\mu \mathrm{m})$ & $S_{\mathrm{tr}}$ & $S_{\text {tr }}$ conf. int. & $S_{\mathrm{dq}}$ & $S_{\mathrm{dq}}$ conf. int. \\
\hline CF 170 & 1.05 & \pm 0.17 & 0.43 & \pm 0.12 & 0.55 & \pm 0.08 \\
\hline$C F 200$ & 0.78 & \pm 0.15 & 0.28 & \pm 0.13 & 0.41 & \pm 0.08 \\
\hline$C F 230$ & 0.70 & \pm 0.09 & 0.22 & \pm 0.10 & 0.40 & \pm 0.04 \\
\hline EAA 170 & 0.41 & \pm 0.03 & 0.02 & \pm 0.00 & 0.13 & \pm 0.03 \\
\hline EAA 200 & 0.40 & \pm 0.03 & 0.02 & \pm 0.00 & 0.11 & \pm 0.01 \\
\hline EAA 230 & 0.42 & \pm 0.04 & 0.03 & \pm 0.01 & 0.13 & \pm 0.02 \\
\hline
\end{tabular}




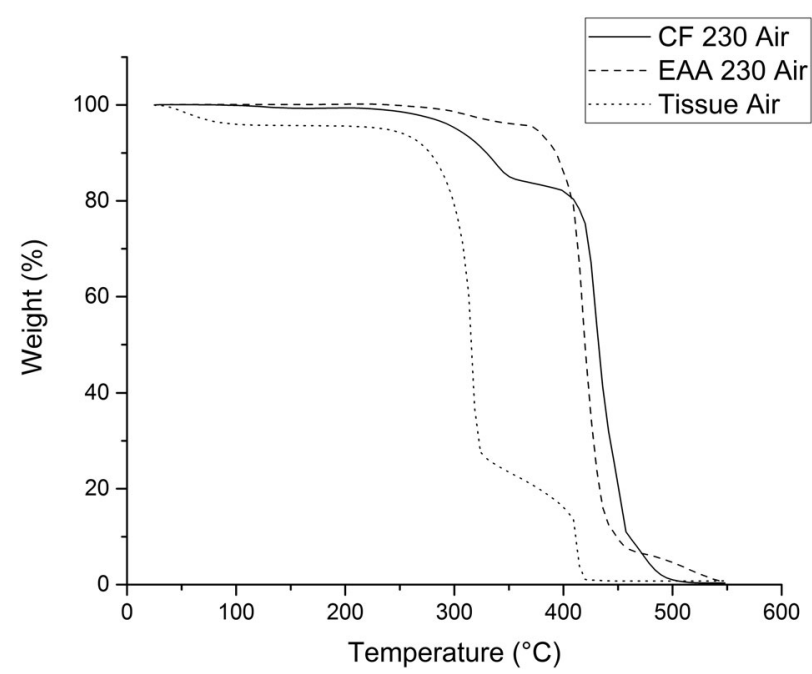

FIG. 7. Thermogravimetric curves showing the thermal degradation of composite $(C F)$, unfilled EAA, and the cellulose fibers in air.

\section{CONCLUSIONS}

The main conclusions arrived at in this study can be summarized as follows:

The color of injection-molded specimens containing cellulose fibers as reinforcing elements is very sensitive to the processing temperature and is associated with the onset of thermal degradation.

Despite the strong effect on the color of the cellulosecontaining composites, the processing temperature had no significant effects on the mechanical properties, the gloss, or the surface topography. There were, however, indications that the composites produced at a higher melt temperature had a slightly smoother surface.

Incorporation of $20 \mathrm{wt} \%$ cellulose into the EAA matrix significantly increased the tensile modulus compared to that of the unfilled polymer, but it had a negative influence on the strength and strain at break, probably associated with the properties of the interface between the two components. The addition of cellulose fibers reduced the gloss and the smoothness of the surface.

The overall thermal degradation of the composites, as revealed by TGA, was determined by the cellulose content, but it was not affected by the processing temperature used in the range studied here.

\section{ACKNOWLEDGMENTS}

The authors thank the Swedish Research Council Formas and Chalmers University of Technology for financial support. J. A. Bristow is gratefully acknowledged for the linguistic revision of the manuscript. Volvo is thanked for the possibilities to measure color and gloss.

\section{REFERENCES}

1. A.K. Bledzki, O. Faruk, and V.E. Sperber, Macromol. Mater. Eng., 291(5), 449 (2006).

2. A.K. Bledzki and J. Gassan, Prog. Polym. Sci., 24(2), 221 (1999).
3. M. Jawaid and H.P.S. Abdul Khalil, Carbohydr. Polym., 86(1), 1 (2011).

4. L.M. Sherman, Plast. Technol., 45, 10 (1999).

5. A. Shalwan and B. Yousif, Mater. Des., 48, 14 (2013).

6. K. Berggren, C. Klason, and J. Kubát, Kunststoffe, 12(2), 69 (1975).

7. C. Klason, J. Kubát, and H.-E. Strömvall, Int. J. Polym. Mater. Polym. Biomater., 10(3), 159 (1984).

8. B.V. Kokta, R. Chen, C. Daneault, and J.L. Valade, Polym. Compos., 4, 229 (1983).

9. C. Miao and W.Y. Hamad, Cellulose, 20, 22221 (2013).

10. K.L. Pickering, M.G. Efendy Aruan, and T.M. Le, Compos. Part A: Appl. Sci. Manuf., 83, 98 (2016).

11. H. Domininghaus, Plastics for Engineers, Hanser Gardner Publications, Munich (1999).

12. D. Panaitescu, D. Donescu, C. Bercu, D. Vuluga, M. Iorga, and M. Ghiurea, Polym. Eng. Sci., 47(8), 1228 (2007).

13. A.K. Bledzki, M. Letman, A. Viksne, and L. Rence, Compos. Part A: Appl. Sci. Manuf., 36(6), 789 (2005).

14. H. Dalväg, C. Klason, and H.-E. Strömvall, Int. J. Polym. Mater., 11(1), 9 (1985).

15. S. Sapieha, J. Pupo, and H. Schreiber, J. Appl. Polym. Sci., 37(1), 233 (1989).

16. A. Mosca Conte, O. Pulci, A. Knapik, J. Bagniuk, R. Del Sole, J. Lojewska, and M. Missori, Phys. Rev. Lett., 108, 158301-1 (2012).

17. F. Shafizadeh and A.G.W. Bradbury, J. Appl. Polym. Sci., 23, 1431 (1979).

18. S. Matsuoka, H. Kawamoto, and S. Saka, Polym. Degrad. Stab., 96(7), 1242 (2011).

19. K. Huff, Visual Assessment and Practical Colorimetry in the Plastics Industry, Bayer AG, Leverkusen (1994).

20. I. Ariño, Appearance Characterisation of Textured Polymeric Surfaces, Doctoral Thesis, Department of Materials and Manufacturing Technology, Chalmers University of Technology (2005).

21. S. Ignell, U. Kleist, and M. Rigdahl, Color. Res. Appl., 34(4), 291 (2008).

22. R. Ariño and A. Boldizar, Int. Polym. Process., 28(4), 429 (2013).

23. R. Ariño and A. Boldizar, Int. Polym. Process., 29(4), 507 (2014).

24. R. Ariño and A. Boldizar, Int. Polym. Process., 28(4), 421 (2013).

25. R. Ariño and A. Boldizar, Polym. Eng. Sci., 52(9), 1951 (2012).

26. M. Le Baillif and K. Oksman, J. Thermoplast. Compos. Mater., 22(2), 115 (2009).

27. International Comission on Illumination (CIE), [Online]. Available: http://www.cie.co.at/. (Accessed Aug 22, 2018).

28. C. Bermudez, A. Matilla, and A. Aguerri, "Confocal Fusion: Towards the Universal Optical 3D Metrology Technology," EUSPEN.

29. R. Leach, ed., Optical Measurement of Surface Topography, Springer-Verlag, Berlin (2011).

30. A. Matilla, J. Mariné, J. Pérez, C. Cadevall, and R. Artigas, Optical Micro-Nanomet. VI, 98900B-1 (2016).

31. ISO 25178-2:2012-Geometrical product specifications (GPS)Surface Texture: Areal-Part 2: Terms, Definitions and Surface 
Texture Parameters, International Organization for Standardization (2012).

32. R. Leach, ed., Characterisation of Areal Surface Texture, Springer-Verlag, Berlin (2013).

33. D. Bondeson and K. Oksman, Compos. Interfaces, 14(7-9), 617 (2007).
34. A. Eisenberg and M. King, Ion-Containing Polymers, Academic Press, New York (1977).

35. F. Pisciotti, I. Ariño, A. Boldizar, and M. Rigdahl, Polym. Eng. Sci., 45, 1557 (2005).

36. E.N. Dalal and K.M. Natale-Hoffman, Color. Res. Appl., 24, 369 (1999). 